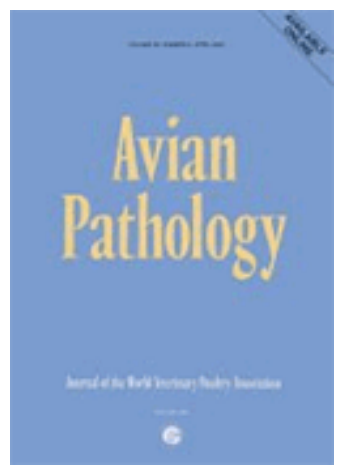

\title{
The effect of commonly used anticoccidials and antibiotics in a subclinical necrotic enteritis model
}

\begin{tabular}{|r|l|}
\hline Journal: & Avian Pathology \\
\hline Manuscript ID: & CAVP-2009-0121.R1 \\
\hline Manuscript Type: & Original Research Paper \\
\hline Author: & 26-Oct-2009 \\
\hline Complete List of Authors: & $\begin{array}{l}\text { Lanckriet, Anouk; University of Ghent, Pathology, bacteriology and } \\
\text { avian diseases } \\
\text { Timbermont, Leen; University of Ghent, Pathology, bacteriology } \\
\text { and avian diseases } \\
\text { De Gussem, Maarten; Alpharma Animal Health } \\
\text { Marien, Maja; Alpharma Animal Health } \\
\text { Vancraeynest, Dieter; Alpharma Animal Health } \\
\text { Haesebrouck, Freddy; University of Ghent, Pathology, bacteriology } \\
\text { and avian diseases } \\
\text { Ducatelle, Richard; University of Ghent, Pathology, bacteriology and } \\
\text { avian diseases } \\
\text { Van Immerseel, Filip; University of Ghent, Pathology, bacteriology } \\
\text { and avian diseases }\end{array}$ \\
\hline Keywords: & $\begin{array}{l}\text { Necrotic enteritis, Clostridium perfringens, ionophore anticoccidials, } \\
\text { antibiotics }\end{array}$ \\
\hline \hline
\end{tabular}

\section{SCHOLARONE \\ Manuscripts}


The effect of commonly used anticoccidials and antibiotics in a subclinical necrotic enteritis model

\section{A. Lanckriet ${ }^{1}$, L. Timbermont ${ }^{1}$, M. De Gussem ${ }^{2}$, M. Marien ${ }^{2}$, D. Vancraeynest ${ }^{2}$, F.} Haesebrouck $^{1}$, R. Ducatelle ${ }^{1}$ and F. Van Immerseel ${ }^{1^{*}}$

${ }^{1}$ Department of Pathology, Bacteriology and Avian Diseases, Research Group Veterinary Public Health and Zoonoses, Faculty of Veterinary Medicine, Ghent University, Salisburylaan 133, B-9820 Merelbeke, Belgium

${ }^{2}$ Alpharma Animal Health, Garden square-Laarstraat 16, 2610 Wilrijk, Belgium

* To whom correspondence should be addressed. Tel: + 32092647448.

Fax: +32 0926474 94. E-mail: filip.vanimmerseel@UGent.be

Short title: Anticoccidials and antibiotics

Received 5 May 2009 


\section{Abstract}

Necrotic enteritis poses an important health risk to broilers. The ionophore anticoccidials lasalocid, salinomycin, maduramicin, narasin and a combination of narasin and nicarbazin were tested in feed for their prophylactic effect on the incidence of necrotic enteritis in a subclinical experimental infection model that uses coccidia as predisposing factor. In addition, drinking water medication with the antibiotics amoxicillin, tylosin and lincomycin was evaluated as curative treatment in the same experimental model. The Minimal Inhibitory Concentrations (MICs) of all antibiotics and anticoccidials were determined in vitro against 51 C. perfringens strains isolated from broilers. The strains examined appeared uniformly susceptible to lasalocid, maduramicin, narasin, salinomycin, amoxicillin and tylosin whereas an extended frequency distribution range of MICs of lincomycin was seen, indicating acquired resistance in thirty-six isolates in the higher range of MICs. Nicarbazin did not inhibit the in vitro growth of the $C$. perfringens strains even at a concentration of $128 \mu \mathrm{g} / \mathrm{ml}$. Supplementation of the diet from day 1 onwards with lasalocid, salinomycin, narasin or maduramicin lead to a reduction in birds with necrotic enteritis lesions as compared to the non-medicated infected control group. A combination product of narasin and nicarbazin had no significant protective effect. Treatment with amoxicillin, lincomycin and tylosin completely stopped the development of necrotic lesions. 


\section{Introduction}

Necrotic enteritis is a disease of major economic importance affecting the poultry industry worldwide. Globally, annual costs attributed to necrotic enteritis are estimated to be over US\$2 billion due to production losses and medical treatments (Anonymous, 2000).

The causative agents of necrotic enteritis are Clostridium perfringens toxinotype A strains that are able to produce the NetB toxin (Engstrom et al., 2003; Gholamiandekhordi et al., 2006; Keyburn et al., 2006; Keyburn et al., 2008). The onset of NE is, however, a multifactorial event in which (sub)clinical coccidiosis is believed to be one of the major predisposing factors. Several field cases have been reported in which coccidiosis preceded or coincided with necrotic enteritis, although clinical coccidiosis will not always result in the development of necrotic enteritis (Long, 1973; Broussard et al., 1986; Droual et al., 1994; Dhillon et al., 2004; Hermans \& Morgan, 2007). Combined experimental infection with species of Eimeria and C. perfringens leads to higher intestinal lesion scores, increased intestinal numbers of $C$. perfringens, increased mortality and reduced weight gain compared to infection with $C$. perfringens alone (Al-Sheikhly \& Al-Saieg, 1980; Shane et al., 1985; Kageyama et al., 1987; Baba et al., 1992; Baba et al., 1997; Williams et al., 2003; Gholamiandehkordi et al., 2007; Park et al., 2008).

Until recently, necrotic enteritis was effectively controlled by mixing antimicrobial growth promoters (AGPs) in the broiler feed (Prescott et al., 1978; Elwinger et al., 1992; Elwinger et al., 1998). Concerns about the potential risk of transmission of antimicrobial resistance, induced in bacterial populations that are carried by domestic animals, towards bacteria infecting humans, drove Norway to ban the use of all AGPs in poultry feed for growth promoting purposes in 1995 . This lead to a rise in necrotic enteritis - affected flocks 
in Norway up to $40 \%$ (Kaldhusdal \& Lovland, 2000). From January $1^{\text {st }} 2006$, the use of all AGPs in poultry feed is also forbidden in the European Union (Regulation (EC) No $1831 / 2003)$.

Since the ban, European farmers rely mostly on curative use of antibiotics like amoxicillin and tylosin, to control necrotic enteritis whenever clinical signs become apparent but no reports exist on the efficiency of these antibiotics to stop the development of necrotic enteritis during an outbreak (Casewell et al., 2003; Hermans \& Morgan, 2007). However, when these curative antibiotics are used without precaution for the treatment of foodproducing animals, they may contribute to the development of antimicrobial resistance to important human drugs (Giguère, 2006, Schwarz et al., 2006). Previous studies reported that C. perfringens strains were susceptible to the antibiotics amoxicillin and tylosin in vitro, but that some broiler isolates showed already acquired resistance against lincomycin (Martel et al., 2004).

The carboxylic ionophore polyether anticoccidials lasalocid, maduramicin, narasin and salinomycin all possess antibacterial activity and inhibit the growth of $C$. perfringens in vitro (Kondo, 1988; Devriese et al., 1993; Martel et al., 2004). These anticoccidials are currently in use in the European Union and therefore, when proven active in vivo, could be useful to the European farmers in the prevention of necrotic enteritis.. In Norway, after the ban of avoparcin, an increase of necrotic enteritis was observed that was believed to be partly leveled out by the introduction of narasin as a feed additive (Grave et al., 2004). 
The present study aims to assess the efficacy of ionophore anticoccidials and a selection of commonly used antibiotics to control necrotic enteritis in a well-established in vivo model (Gholamiandehkordi et al., 2007; Timbermont et al., 2008).

\section{Materials and methods}

Strains and vaccines. Fifty one $C$. perfringens type A strains belonging to different genotypes, as analyzed by Pulsed Field Gel Electrophoresis (PFGE), were included. Thirtyfive strains were isolated from broiler chickens in Belgium: 26 strains from clinically healthy broiler chickens and 9 strains from broilers suffering from necrotic enteritis (Gholamiandekhordi et al., 2006). Sixteen Danish C. perfringens isolates from necrotic enteritis cases were kindly provided by Dr. L. Bjerrum (Nauerby et al., 2003). C. perfringens strain 56, the strain used in the in vivo trials, was isolated from the intestine of a broiler chicken with severe necrotic gut lesions. It belongs to toxinotype A (no beta2 or enterotoxin genes) and produces moderate amounts of alpha toxin in vitro (Gholamiandekhordi et al., 2006). The strain carries the netB gene and has been used previously to induce necrotic enteritis in an in vivo model (Timbermont et al., 2008). Before inoculation of the chickens, the bacteria were cultured for $24 \mathrm{~h}$ at $42^{\circ} \mathrm{C}$ in Brain Heart Infusion broth (BHI, Oxoid, Basingstoke, England) in an anaerobic cabinet. The commercial vaccine Nobilis Gumboro D78 (Intervet, Mechelen, Belgium) and the anticoccidial vaccine Paracox $-5^{\mathrm{TM}}$ (ScheringPlough Animal Health, Brussels, Belgium), containing live precocious oocysts of Eimeria acervulina (E. acervulina), E. maxima (two lines), E. mitis and E. tenella were used to create 
predisposing lesions for necrotic enteritis.

Minimum inhibitory concentrations of anticoccidials and antibiotics. All antibiotics and anticoccidials were obtained from Alpharma Animal Health (Bridgewater NJ, USA) except for narasin and nicarbazin (Sigma, St. Louis Mo, USA). Minimal inhibitory concentrations (MICs) of all antibiotics and anticoccidials were tested using the agar dilution method based on the guidelines of the CLSI (2008) (formerly NCCLS). Strains were inoculated onto Columbia agar supplemented with 5\% sheep blood (Oxoid) and then incubated in an anaerobic atmosphere for $24 \mathrm{~h}$ at $37^{\circ} \mathrm{C}$. Cultures were checked for purity. Up to 5 colonies were then suspended in Phosphate Buffered Saline (PBS) at $\mathrm{pH} 7.2$ to a density of 0.5 McFarland, as determined with an ATB 1550 reader. Using a MAST inoculum applicator, a 1/10 dilution of this suspension was inoculated on Mueller Hinton II agar (Oxoid) plates containing serial two-fold dilutions of the antibiotics and anticoccidials. The concentration ranges tested for each product were 0.03 to $128 \mu \mathrm{g} / \mathrm{ml}$. The plates were incubated in an anaerobic atmosphere and observed after $24 \mathrm{~h}$ for bacterial growth. The MIC was defined as the lowest concentration producing no visible growth. One agar plate without anticoccidials or antibiotics was included to verify growth of all strains tested. Strains used for quality control were Staphylococcus aureus ATCC 29213 and Escherichia coli ATCC 25922.

Birds and housing. In vivo necrotic enteritis trials using experimental inoculations were performed with Ross 308 broiler chickens that were obtained as one-day-old chicks from a commercial hatchery. Per trial, all treatment groups were housed in the same room. The birds were reared in cages with a density of $28 \mathrm{birds} / 1 \mathrm{~m}^{2}$ on wood shavings. All cages were 
separated by solid walls to prevent contact between birds from different treatment groups. Before the trial, the rooms were decontaminated with Metatectyl HQ (Clim'o Medic ${ }^{\circledR}$, Metatecta, Belgium) and a commercial anticoccidial disinfectant (OOCIDE, DuPont Animal Health Solutions, Wilmington, US). The chickens were divided in groups of 28 animals. They received ad libitum drinking water and feed. A $23 \mathrm{~h} / 1 \mathrm{~h}$ light/darkness program was applied. The animal experiments were carried out according to the recommendations and following approval of the Ethical Committee of the Faculty of Veterinary Medicine, Ghent University.

In vivo necrotic enteritis model. Trials were performed as described previously (Gholamiandehkordi et al., 2007). In short, broilers were fed a wheat/rye-based (43\%/7.5\%) diet, with soybean meal as protein source. The feed composition was described by Gholamiandehkordi et al. (2007). Gumboro vaccine was given in the drinking water on day 16 in all groups. From day 17 onwards, the same diet was used with the exception that fishmeal $(30 \%)$ replaced soy bean as protein source. All groups were orally challenged using a plastic tube (three times a day) with approximately $4 \times 10^{8} \mathrm{cfu} C$. perfringens bacteria on days $17,18,19$ and 20. On day 18, all birds were orally inoculated with a ten-fold dose of Paracox $-5^{\mathrm{TM}}$. The vaccine was diluted in $1 \mathrm{ml}$ of water and given orally with a syringe to each chicken individually. Each chicken got approximate numbers of sporulated oocysts: $E$. acervulina HP, 5000 - 6500; E. maxima CP, 2000 - 2300;

E. maxima MFP, 1000 - 1300; E. mitis HP, 10000 - 13000; E. tenella HP, 5000 - 6500.

On days 22, 23 and 24, nine animals of each group were euthanized by intravenous T61 (Intervet, Mechelen, Belgium) injection. Necrotic enteritis lesion scoring and sample 
collection was performed, as described below.

In the first trial, from day 1 onwards, anticoccidials were mixed in the diet of 5 out of 7 groups according to the recommendations of the suppliers at a concentration of $75 \mathrm{ppm}$ for lasalocid, $70 \mathrm{ppm}$ for salinomycin, $5 \mathrm{ppm}$ for maduramicin, $70 \mathrm{ppm}$ for narasin when used on its own, and $50 \mathrm{ppm}$ for narasin and $50 \mathrm{ppm}$ for nicarbazin when present in the combined product. All anticoccidials were obtained from Alpharma Animal Health except for narasin and the combination product of narasin and nicarbazin (Elanco, Greenfield IN, USA). Analysis of the feed samples was performed by HPLC in accredited laboratories and confirmed the concentration of the test substances. Two control groups were included: a non-medicated group receiving only the 10 -fold dose of the Paracox $-5^{\mathrm{TM}}$ vaccine and a non-medicated group receiving both the 10-fold dose of Paracox-5 and the $C$. perfringens infection (positive control).

In the second trial, seven out of nine groups were treated from day 20 to 24 with antibiotics in the drinking water at concentrations of 50,100 and $150 \mathrm{~g} / 1000$ liter for amoxicillin, 50 and $150 \mathrm{~g} / 1000$ liter for lincomycin and 100 and $200 \mathrm{~g} / 1000$ liter for tylosin. The same two non-medicated control groups were included as described for trial 1.

Macroscopical lesions scoring. Intestinal lesions in the small intestine (duodenum to ileum) were scored as described by Keyburn et al. (2006). Birds with lesion scores of 2 (1 to 5 lesions) or more were classified as necrotic enteritis positive.

Statistical analysis. The data were analyzed with SPSS Statistics 17.0 software (SPSS Inc., Chicago) using the binary logistic regression method to compare the number of necrotic 
enteritis positive animals (lesion score $\geq 2$ ) within the test groups. Bonferroni's correction for multiple comparisons was applied $(\mathrm{P}<0.05 / \mathrm{n})$ and significance was determined at $\mathrm{P}<0.007$ for the first trial and $\mathrm{P}<0.0055$ for the second trial.

\section{Results}

\section{Minimal inhibitory concentrations of the tested anticoccidials and antibiotics. The} results for the reference strains S. aureus ATCC 29213 and E. coli ATCC 25922 were within acceptable CLSI quality control limits for amoxicillin, lincomycin and tylosin. The MIC values for 51 broiler chicken isolates are shown in Table 1. The MIC of the lincosamide antibiotic lincomycin showed an extended frequency distribution range between 0.25 and 16 $\mu \mathrm{g} / \mathrm{ml}$, indicating acquired resistance in isolates in the higher range of MICs. Acquired resistance was not detected to the other antibiotics and anticoccidials tested. The C. perfringens isolates examined were highly susceptible to the ionophore antibiotics lasalocid, narasin, maduramicin and salinomycin. Nicarbazin did not inhibit the in vitro growth of the $C$. perfringens isolates even at a concentration of $128 \mu \mathrm{g} / \mathrm{ml}$.

In vivo trials. Birds, that died before the infection started, were necropsied to determine the cause of death. None of the birds showed necrotic lesions in their intestines. Table 2 summarizes the number of birds having necrotic lesions in their small intestine in the different treatment groups. The intestinal lesions presented as multiple necrotic foci, mostly in the duodenum and jejunum. No necrotic enteritis lesions were observed in the negative control group, i.e. the untreated group only inoculated with a 10-fold dose of Paracox-5. In 
the positive control group, more than $50 \%$ of the birds presented lesions.

Mixing lasalocid, narasin or salinomycin in the feed resulted in a statistically significant decrease in the number of birds having macroscopic necrotic lesions compared to the infected, untreated positive control group $(\mathrm{P}<0.007)$. The decrease in number of positive animals obtained with maduramicin was borderline non-significant $(\mathrm{P}=0.009)$. When the results for narasin, lasalocid and salinomycin were compared with each other, there was no statistically significant difference in number of positive birds between these groups. The addition of a combination of narasin $(50 \mathrm{ppm})$ and nicarbazin to the feed was less effective than narasin $(70 \mathrm{ppm})$ alone and did not cause a significant decrease in the number of animals compared to the control group.

In trial 2, all three antibiotics tested completely stopped the development of necrotic enteritis lesions in the gut, resulting in zero birds with lesions in all medicated groups already at the lowest concentration tested.

\section{Discussion}

The results obtained in the experimental infection model clearly show a significant decrease in number of broilers with necrotic enteritis gut lesions when lasalocid, salinomycin or narasin were mixed in the feed from day 1 onwards. All broiler $C$. perfringens isolates tested were uniformly sensitive to these anticoccidials in vitro. The results obtained in the in vivo necrotic enteritis model confirm earlier reports in which narasin and salinomycin were shown to have beneficial effects on the control of necrotic enteritis in broilers in vivo (Elwinger et al., 1992; Bolder et al., 1999; Waldenstedt et al., 1999; Engberg et al., 2000; 
Vissiennon et al., 2000; Brennan et al., 2001a; Johansen et al., 2007). Narasin significantly reduces the mean necrotic enteritis lesions scores and necrotic enteritis associated mortality compared to control groups (Vissiennon et al., 2000; Brennan et al., 2001 a). Salinomycin has been proven to decrease both the caecal count and prevalence of $C$. perfringens in broilers and reduces the shedding of $C$. perfringens after experimental infection (Bolder et al., 1999; Engberg et al., 2000; Johansen et al., 2007). This anticoccidial was also able to diminish the severity of the lesions due to necrotic enteritis in an experimental infection model (Elwinger et al., 1998; Engberg et al., 2000; Jackson et al., 2003).

The inhibitory activity of lasalocid or maduramicin against $C$. perfringens in vivo in broilers has not been reported before. The efficiency of lasalocid in reducing the number of birds with lesions was comparable to that of salinomycin and narasin.

In article 11 of the European Council regulation 1831/2003, the European Union states that the use of anticoccidials as feed additives should be evaluated by December 2012 (Regulation, 2003). However, in 2008, the European Commission submitted a report on the use of these substances as feed additives and existing alternatives to the Council and the European Parliament (COM, 2008). In this report, the European Commission clearly recommends to maintain the current legislation and allow the use of anticoccidials, including ionophores as feed additives because of the lack of alternatives and to preserve the economic viability of the poultry industry. Since then, it is unclear whether the European Council will consider the phase-out of anticoccidials as feed-additives and change the regulation for their use or whether the European Council will follow the advice of the European Commission. 
Amoxicillin, tylosin and lincomycin were equally effective in abolishing the development of necrotic enteritis after infection with the virulent strain 56, indicating that these antibiotics can be used to treat necrotic enteritis outbreaks. These results confirm previous publications in which tylosin was shown to have beneficial effects on the occurrence of lesions and mortality due to necrotic enteritis (Stutz \& Lawton, 1984; Waldenstedt et al., 1999; Vissiennon et al., 2000; Brennan et al., 2001b; Collier et al., 2003). Lincomycin is also known to reduce necrotic enteritis associated mortality (Maxey \& Page, 1977; Truscott \& Al-Sheikhly, 1977; Hamdy et al., 1983). To our knowledge, no reports on field trials using amoxicillin to treat necrotic enteritis in broilers exist

In contrast to a previous report, among the broiler isolates tested, there was no tendency towards a bimodal distribution of MICs of amoxicillin (Martel et al., 2004). The MICs for lincomycin and tylosin were in the same range as those described in 2004 (Martel et al., 2004). No CLSI or EUCAST breakpoints or cut-off values are available for lincomycin (http://www.eucast.org, .http://www.clsi.org). Martel et al. (2004) set the wild type cut-off value for lincomycin, differentiating isolates with normal susceptibility from those with acquired resistance at $1 \mu \mathrm{g} / \mathrm{ml}$. When applied to our results, thirty-six of the fiftyone isolates tested showed acquired resistance, including the strain 56 used for the in vivo trial, which had a MIC of $4 \mu \mathrm{g} / \mathrm{ml}$. Nevertheless, in the present study, using strain 56 as challenge, lincomycin treatment successfully stopped the development of necrotic lesions, indicating that the clinical breakpoint of lincomycin against enteric $C$. perfringens infections in poultry is higher than the wild type cut off value proposed by Martel et al. (2004). Although prolonged use of ionophore anticoccidials might induce reduced susceptibility or antibiotic resistance in the intestinal bacterial population, as described for Staphylococcus sp. 
and Enterococcus sp., these ionophores have a rather limited spectrum and are not used in human medicine (Butaye et al., 2003, Dowling, 2006). Furthermore, no cross-resistance with currently used antibiotics in human medicine are known so there is no danger of transmission of antibiotic resistance selected in animals towards humans (Callaway et al., 2003). In contrast, amoxicillin, lincosamids and macrolides are commonly used in both veterinary and human medicine. Cross resistance among macrolides, lincosamids and streptogramin groupB antibiotics is known to occur (Giguere, 2006, Schwarz et al., 2006). Therefore, the authors recommend to use amoxicillin, lincomycin and tylosin only in acute outbreaks of necrotic enteritis but to avoid recurrent exposure of the intestinal flora to these antibiotics. Both for ionophore anticoccidials and amoxicillin, lincomycin and tylosin, the induction of antibiotic resistance should be monitored regularly.

In conclusion, it was shown in an experimental infection model that ionophore anticoccidials may contribute to the control of necrotic enteritis in broiler chickens. Further field trials including a larger number of animals, are necessary to verify our results. Amoxicillin, tylosin and lincomycin were shown to be effective in curing necrotic enteritis outbreaks. Acquired resistance was detected only to lincomycin.

\section{Acknowledgements}

We would like to thank Renzo Vercammen and Arlette Van de Kerckhove for their skilful technical assistance. This work was supported by the Institute for Science and Technology, Flanders (IWT). Dr. F. Van Immerseel is supported by a Postdoctoral Research Grant of the Research Foundation - Flanders (FWO) and by the Research Fund of Ghent University. 


\section{References}

Al-Sheikhly, F. \& Al-Saieg, A. (1980). Role of coccidia in the occurrence of necrotic enteritis of chickens. Avian Diseases, 24, 324-333.

Anonymous (2000). World growth continues. Poultry International, 39, 8-14.

Baba, E., Fuller, A. L., Gilbert, J. M., Thayer, S. G. \& McDougald, L. R. (1992). Effects of Eimeria brunetti infection and dietary zinc on experimental induction of necrotic enteritis in broiler chickens. Avian Diseases, 36, 59-62.

Baba, E., Ikemoto, T., Fukata, T., Sasai, K., Arakawa, A. \& McDougald, L. R. (1997). Clostridial population and the intestinal lesions in chickens infected with Clostridium perfringens and Eimeria necatrix. Veterinary Microbiology, 54, 301-308.

Bolder, N. M., Wagenaar, J. A., Putirulan, F. F., Veldman, K. T. \& Sommer, M. (1999). The effect of flavophospholipol (Flavomycin) and salinomycin sodium (Sacox) on the excretion of Clostridium perfringens, Salmonella enteritidis, and Campylobacter jejuni in broilers after experimental infection. Poultry Science, 78, 1681-1689.

Brennan, J., Bagg, R., Barnum, D., Wilson, J. \& Dick, P. (2001a). Efficacy of narasin in the prevention of necrotic enteritis in broiler chickens. Avian Diseases, 45, 210-214.

Brennan, J., Moore, G., Poe, S. E., Zimmermann, A., Vessie, G., Barnum, D. A. \& Wilson, J. (2001b). Efficacy of in-feed tylosin phosphate for the treatment of necrotic enteritis in broiler chickens. Poultry Science, 80, 1451-1454.

Broussard, C. T., Hofacre, C. L., Page, R. K. \& Fletcher, O. J. (1986). Necrotic enteritis in cage-reared commercial layer pullets. Avian Diseases, 30, 617-619. 
Butaye, P., Devriese, L. A. \& Haesebrouck, F. (2003). Antimicrobial growth promoters used in animal feed: effects of less well known antibiotics on gram-positive bacteria. Clinical Microbiology Reviews, 16, 175-188.

Callaway, T. R., Edrington, T. S., Rychlik, J. L., Genovese, K. J., Poole, T. L., Jung, Y. S., Bischoff, K. M., Anderson, R. C. \& Nisbet, D. J. (2003). Ionophores: their use as ruminant growth promotants and impact on food safety. Current Issues in Intestinal Microbiology, 4, 43-51.

Casewell, M., Friis, C., Marco, E., McMullin, P. \& Phillips, I. (2003). The European ban on growth-promoting antibiotics and emerging consequences for human and animal health. Journal of Antimicrobial Chemotherapy, 52, 159-161.

CLSI (2008). Performance Standards for Antimicrobial Disk and Dilution Susceptibility Tests for Bacteria Isolated From Animals, Approved Standard, 3rd Ed., M13-A3, Vol. 28 No. 8

Collier, C. T., van der Klis, J. D., Deplancke, B., Anderson, D. B. \& Gaskins, H. R. (2003). Effects of tylosin on bacterial mucolysis, Clostridium perfringens colonization, and intestinal barrier function in a chick model of necrotic enteritis. Antimicrobial Agents and Chemotherapy, 47, 3311-3317.

COM (2008). COM/2008/0233. Report from the Commission to the Council and the European Parliament on the use of coccidiostats and histomonostats as feed additives, submitted pursuant to article 11 of regulation (EC) no 1831/2003 of the European Parliament and of the Council of 22 September 2003 on additives for use in animal nutrition. http://www.ipex.eu/ipex/cms/home/Documents/dossier_COM20080233 
Devriese, L. A., Daube, G., Hommez, J. \& Haesebrouck, F. (1993). In vitro susceptibility of Clostridium perfringens isolated from farm animals to growth-enhancing antibiotics. Journal of Applied Bacteriology, 75, 55-57.

Dhillon, A. S., Roy, P., Lauerman, L., Schaberg, D., Weber, S., Bandli, D. \& Wier, F. (2004). High mortality in egg layers as a result of necrotic enteritis. Avian Diseases, 48, 675-680.

Dowling, M. (2006). Miscellaneous antimicrobials: Ionophores, nitrofurans, nitroimidazoles, rifamycins, oxazolidinones, and others. In S. Giguère, J.F. Prescott, J.D. Baggot, R.D. Walker, \& P.M. Dowling. (2006). Antimicrobial Therapy in Veterinary Medicine. $4^{\text {th }}$ edn (pp. 285-300). Ames: Blackwel publishing.

Droual, R., Shivaprasad, H. L. \& Chin, R. P. (1994). Coccidiosis and necrotic enteritis in turkeys. Avian Diseases, 38, 177-183.

Elwinger, K., Schneitz, C., Berndtson, E., Fossum, O., Teglof, B. \& Engstom, B. (1992). Factors affecting the incidence of necrotic enteritis, caecal carriage of Clostridium perfringens and bird performance in broiler chicks. Acta Veterinaria Scandinavica, $33,369-378$.

Elwinger, K., Berndtson, E., Engstrom, B., Fossum, O. \& Waldenstedt, L. (1998). Effect of antibiotic growth promoters and anticoccidials on growth of Clostridium perfringens in the caeca and on performance of broiler chickens. Acta Veterinaria Scandinavica, 39, 433-441.

Engberg, R. M., Hedemann, M. S., Leser, T. D. \& Jensen, B. B. (2000). Effect of zinc bacitracin and salinomycin on intestinal microflora and performance of broilers. Poultry Science, 79, 1311-1319. 
Engstrom, B. E., Fermer, C., Lindberg, A., Saarinen, E., Baverud, V. \& Gunnarsson, A. (2003). Molecular typing of isolates of Clostridium perfringens from healthy and diseased poultry. Veterinary Microbiology, 94, 225-235.

Gholamiandehkordi, A. R., Timbermont, L., Lanckriet, A., Van Den Broeck, W., Pedersen, K., Dewulf, J., Pasmans, F., Haesebrouck, F., Ducatelle, R. \& Van Immerseel, F. (2007). Quantification of gut lesions in a subclinical necrotic enteritis model. Avian Pathology, 36, 375-382.

Gholamiandekhordi, A. R., Ducatelle, R., Heyndrickx, M., Haesebrouck, F. \& Van Immerseel, F. (2006). Molecular and phenotypical characterization of Clostridium perfringens isolates from poultry flocks with different disease status. Veterinary Microbiology, 113, 143-152.

Giguère, S. (2006). Lincosamides, pleuromutulins, and streptogramins. In S. Giguère, J.F. Prescott, J.D. Baggot, R.D. Walker, \& P.M. Dowling. (2006). Antimicrobial Therapy in Veterinary Medicine. $4^{\text {th }}$ edn (pp. 179-190). Ames: Blackwel publishing.

Grave, K., Kaldhusdal, M. C., Kruse, H., Harr, L. M. \& Flatlandsmo, K. (2004). What has happened in Norway after the ban of avoparcin? Consumption of antimicrobials by poultry. Preventive Veterinary Medicine, 62, 59-72.

Hamdy, A. H., Thomas, R. W., Yancey, R. J. \& Davis, R. B. (1983). Therapeutic effect of optimal lincomycin concentration in drinking water on necrotic enteritis in broilers. Poultry Science, 62, 589-591.

Hermans, P. G. \& Morgan, K. L. (2007). Prevalence and associated risk factors of necrotic enteritis on broiler farms in the United Kingdom, a cross-sectional survey. Avian Pathology, 36, 43-51. 
Jackson, M. E., Anderson, D. M., Hsiao, H. Y., Mathis, G. F. \& Fodge, D. W. (2003). Beneficial effect of beta-mannanase feed enzyme on performance of chicks challenged with Eimeria sp. and Clostridium perfringens. Avian Diseases, 47, 759763.

Johansen, C. H., Bjerrum, L. \& Pedersen, K. (2007). Impact of salinomycin on the intestinal microflora of broiler chickens. Acta Veterinaria Scandinavica, 49, 30.

Kageyama, A., Fukata, T., Baba, E. \& Arakawa, A. (1987). The influence of various bacteria on the cecal mucosa of monoflora chickens infected with Eimeria tenella. A scanning electron microscopic study. Zentralblatt für Bakteriologie, Mikrobiologie und Hygiene, 265, 353-359.

Kaldhusdal, M. \& Lovland, A. (2000). Necrotic enteritis: The economical impact of Clostridium perfringens is greater than anticipated. World Poultry, 16, 50-51.

Keyburn, A. L., Sheedy, S. A., Ford, M. E., Williamson, M. M., Awad, M. M., Rood, J. I. \& Moore, R. J. (2006). Alpha-toxin of Clostridium perfringens is not an essential virulence factor in necrotic enteritis in chickens. Infection and Immunity, 74, 64966500.

Keyburn, A. L., Boyce, J. D., Vaz, P., Bannam, T. L., Ford, M. E., Parker, D., Di Rubbo, A., Rood, J. I. \& Moore, R. J. (2008). NetB, a new toxin that is associated with avian necrotic enteritis caused by Clostridium perfringens. PLoS Pathogens, 4, e26.

Kondo, F. (1988). In vitro lecithinase activity and sensitivity to 22 antimicrobial agents of Clostridium perfringens isolated from necrotic enteritis of broiler chickens. Research in Veterinary Science, 45, 337-340. 
Long, J. R. (1973). Necrotic enteritis in broiler chickens. I. A review of the literature and the prevalence of the disease in Ontario. Canadian Journal of Comparative Medicine, 37, 302-308.

Martel, A., Devriese, L. A., Cauwerts, K., De Gussem, K., Decostere, A. \& Haesebrouck, F. (2004). Susceptibility of Clostridium perfringens strains from broiler chickens to antibiotics and anticoccidials. Avian Pathology, 33, 3-7.

Maxey, B. W. \& Page, R. K. (1977). Efficacy of lincomycin feed medication for the control of necrotic enteritis in broiler-type chickens. Poultry Science, 56, 1909-1913. Nauerby, B., Pedersen, K. \& Madsen, M. (2003). Analysis by pulsed-field gel electrophoresis of the genetic diversity among Clostridium perfringens isolates from chickens. Veterinary Microbiology, 94, 257-266.

Park, S. S., Lillehoj, H. S., Allen, P. C., Park, D. W., FitzCoy, S., Bautista, D. A. \& Lillehoje, E. P. (2008). Immunopathology and cytokine responses in broiler chickens coinfected with Eimeria maxima and Clostridium perfringens with the use of an animal model of necrotic enteritis. Avian Diseases, 52, 14-22.

Prescott, J. F., Sivendra, R. \& Barnum, D. A. (1978). The use of bacitracin in the prevention and treatment of experimentally-induced necrotic enteritis in the chicken. Canadian Veterinary Journal, 19, 181-183.

Regulation (2003). Regulation (EC) No 1831/2003 of the European Parliament and of the Council of 22 September 2003 on additives for use in animal nutrition. Official Journal of the European Union, L 268, 29-43. 
Schwarz, S., Cloeckaert, A. \& Roberts, M.C. (2006). Mechanisms and spread of bacterial resistance to antimicrobial agents. In F.M. Aarestrup. (2006). Antimicrobial resistance in bacteria of animal origin.1st edn (pp. 73-99). Washington: ASM press.

Shane, S. M., Gyimah, J. E., Harrington, K. S. \& Snider, T. G., 3rd. (1985). Etiology and pathogenesis of necrotic enteritis. Veterinary Research Communications, 9, 269-287.

Stutz, M. W. \& Lawton, G. C. (1984). Effects of diet and antimicrobials on growth, feed efficiency, intestinal Clostridium perfringens, and ileal weight of broiler chicks. Poultry Science, 63, 2036-2042.

Timbermont, L., Lanckriet, A., Gholamiandehkordi, A. R., Pasmans, F., Martel, A., Haesebrouck, F., Ducatelle, R. \& Van Immerseel, F. (2008). Origin of Clostridium perfringens isolates determines the ability to induce necrotic enteritis in broilers. Comparative Immunology Microbiology and Infectious Diseases, 32, 503-512.

Truscott, R. B. \& Al-Sheikhly, F. (1977). Reproduction and treatment of necrotic enteritis in broilers. American Journal of Veterniary Research, 38, 857-861.

Vissiennon, T., Kroger, H., Kohler, T. \& Kliche, R. (2000). Effect of avilamycin, tylosin and ionophore anticoccidials on Clostridium perfringens enterotoxaemia in chickens. Berliner Münchner Tierarztliche Wochenschrift, 113, 9-13.

Waldenstedt, L., Lunden, A., Elwinger, K., Thebo, P. \& Uggla, A. (1999). Comparison between a live, attenuated anticoccidial vaccine and an anticoccidial ionophore, on performance of broilers raised with or without a growth promoter, in an initially Eimeria-free environment. Acta Veterinaria Scandinavica, 40, 11-21.

Williams, R. B., Marshall, R. N., La Ragione, R. M. \& Catchpole, J. (2003). A new method for the experimental production of necrotic enteritis and its use for studies on the 
relationships between necrotic enteritis, coccidiosis and anticoccidial vaccination of chickens. Parasitology Research, 90, 19-26.

Table 1. Minimal Inhibitory Concentrations (MIC) of various agents for 51 Clostridium perfringens strains of broiler chicken origin

\begin{tabular}{|c|c|c|c|c|c|c|c|c|c|c|c|c|c|}
\hline \multirow[t]{2}{*}{ Compound } & \multicolumn{13}{|c|}{ Number of strains with MIC $(\mu \mathrm{g} / \mathrm{ml})$ of } \\
\hline & $\leq 0.03$ & 0.06 & 0.12 & 0.25 & 0.5 & 1 & 2 & 4 & 8 & 16 & 32 & 64 & $\geq 128$ \\
\hline amoxicillin & $46^{\mathrm{a}}$ & 5 & - & - & - & - & - & - & - & - & - & - & - \\
\hline lasalocid & - & - & 34 & 17 & - & - & - & - & - & - & - & - & - \\
\hline lincomycin & - & - & - & 6 & 9 & 3 & 15 & 11 & 6 & 1 & - & - & - \\
\hline maduramicin & - & - & - & - & 29 & 22 & - & - & - & - & - & - & - \\
\hline narasin & - & 7 & 44 & - & - & - & - & - & - & - & - & - & - \\
\hline nicarbazin & - & - & - & - & - & - & - & - & - & - & - & - & 51 \\
\hline salinomycin & - & - & 30 & 21 & - & - & - & - & - & - & - & - & - \\
\hline tylosin & - & - & - & - & 45 & 6 & - & - & - & - & - & - & - \\
\hline
\end{tabular}

${ }^{\mathrm{a}}$ For each antibiotic, the number of isolates sharing the same MIC as strain 56 used in the in vivo trial is shown in bold 
Table 2. Number of birds with macroscopic necrotic enteritis lesions (lesion score $\geq 2$ ) on each sampling day

\begin{tabular}{|c|c|c|c|c|c|}
\hline Trial & Group & Day 22 & Day 23 & Day 24 & Total \\
\hline \multirow[t]{7}{*}{1} & lasalocid $75 \mathrm{ppm}$ & $2 / 10$ & $0 / 9$ & $2 / 9$ & $4 / 28^{\mathrm{a}}$ \\
\hline & salinomycin $70 \mathrm{ppm}$ & $1 / 9$ & $2 / 9$ & $2 / 8$ & $5 / 26^{\mathrm{a}}$ \\
\hline & maduramicin 5 ppm & $3 / 9$ & $2 / 9$ & $1 / 8$ & $6 / 26$ \\
\hline & narasin $70 \mathrm{ppm}$ & $0 / 9$ & $1 / 9$ & $1 / 9$ & $2 / 27^{\mathrm{a}}$ \\
\hline & narasin $50 \mathrm{ppm}+$ nicarbazin $50 \mathrm{ppm}$ & $4 / 9$ & $4 / 9$ & $2 / 9$ & $10 / 27$ \\
\hline & non-medicated, infected control & $5 / 10$ & $7 / 9$ & $5 / 9$ & $17 / 28$ \\
\hline & non-medicated, uninfected control & $0 / 9$ & $0 / 9$ & $0 / 9$ & $0 / 27^{\mathrm{a}}$ \\
\hline \multirow[t]{9}{*}{2} & amoxicillin $50 \mathrm{~g} / 1000$ liter & $0 / 9$ & $0 / 9$ & $0 / 9$ & $0 / 27^{b}$ \\
\hline & amoxicillin $100 \mathrm{~g} / 1000$ liter & $0 / 9$ & $0 / 9$ & $0 / 9$ & $0 / 27^{b}$ \\
\hline & amoxicillin $150 \mathrm{~g} / 1000$ liter & $0 / 9$ & $0 / 9$ & $0 / 9$ & $0 / 27^{\mathrm{b}}$ \\
\hline & lincomycin $50 \mathrm{~g} / 1000$ liter & $0 / 9$ & $0 / 9$ & $0 / 9$ & $0 / 27^{b}$ \\
\hline & lincomycin $150 \mathrm{~g} / 1000$ liter & $0 / 9$ & $0 / 9$ & $0 / 9$ & $0 / 27^{b}$ \\
\hline & tylosin $100 \mathrm{~g} / 1000$ liter & $0 / 9$ & $0 / 9$ & $0 / 9$ & $0 / 27^{\mathrm{b}}$ \\
\hline & tylosin $200 \mathrm{~g} / 1000$ liter & $0 / 9$ & $0 / 9$ & $0 / 9$ & $0 / 27^{\mathrm{b}}$ \\
\hline & non-medicated, infected control & $4 / 9$ & $5 / 9$ & $5 / 9$ & $14 / 27$ \\
\hline & non-medicated, uninfected control & $0 / 8$ & $0 / 8$ & $0 / 8$ & $0 / 24^{b}$ \\
\hline
\end{tabular}

${ }^{\mathrm{a}, \mathrm{b}}$ Values with superscripts differ significantly $(\mathrm{P}<0.007$ for trial 1 and $\mathrm{P}<0.0055$ for trial 2) from the non-medicated, infected control in the first $\left(^{a}\right)$ and second $\left({ }^{b}\right)$ trial. 